\title{
Excitatory Modulation in the Cochlear Nucleus through Group I Metabotropic Glutamate Receptor Activation
}

\author{
Soham Chanda and Matthew A. Xu-Friedman \\ Department of Biological Sciences, University at Buffalo, State University of New York, Buffalo, New York 14260
}

Activation of group I metabotropic glutamate receptors (mGluRs) has been suggested to modulate development of auditory neurons. However, the acute effects of mGluR activation on physiological response properties are unclear. To address this, we studied the effects of mGluRs in bushy cells (BCs) of the mammalian anteroventral cochlear nucleus (AVCN). Activation of mGluRs with dihydroxyphenylglycine (DHPG) caused depolarization of BCs in mice as old as P42, but did not affect neurotransmitter release by presynaptic auditory nerve (AN) fibers. Application of mGluR antagonists indicated that mGluRs are tonically active, and are highly sensitive to small elevations in ambient glutamate by the glutamate reuptake blocker threo- $\beta$-benzyloxyaspartic acid (TBOA). mGluR-mediated depolarization enhanced the firing probability in response to AN stimulation, and reduced the latency and jitter. Furthermore, excitation through postsynaptic mGluRs can significantly counterbalance the inhibitory effects of presynaptic $\mathrm{GABA}_{\mathrm{B}}$ receptors. Thus, interaction between these two modulatory pathways may provide additional flexibility for fine-tuning the $\mathrm{BC}$ relay.

\section{Introduction}

In the auditory pathway, the effects of group I mGluRs have been studied with most emphasis on their contribution to rises in intracellular calcium (Zirpel and Rubel, 1996; Ene et al., 2007; Martinez-Galan et al., 2010) and endocannabinoid release (Kushmerick et al., 2004). mGluR activation can also have electrophysiological consequences (Anwyl, 1999; Ferraguti et al., 2008). However, it is not well understood how mGluR activation would affect firing properties of auditory neurons, nor how it would interact with other modulatory influences.

We addressed the functional consequences of mGluR activation in the anteroventral cochlear nucleus (AVCN). The AVCN contains bushy cells (BCs), which receive direct synaptic input from auditory nerve (AN) fibers through large, glutamatergic synapses called "endbulbs of Held" (Brawer and Morest, 1975; Lorente de Nó, 1981; Limb and Ryugo, 2000). BCs relay the temporal information in AN spike trains to higher centers for sound localization (Grothe et al., 2010). Endbulbs show short-term depression during high-frequency activity (Oleskevich and Walmsley, 2002; Wang and Manis, 2008; Yang and Xu-Friedman, 2008; Chanda and Xu-Friedman, 2010a,b), and modulation in response to $\mathrm{GABA}_{\mathrm{B}}$ receptor $\left(\mathrm{GABA}_{\mathrm{B}} \mathrm{R}\right.$ ) activation (Chanda and $\mathrm{Xu}$-Friedman, 2010a). Both these processes reduce the likelihood of $\mathrm{BC}$ response to $\mathrm{AN}$ activity, raising the question of whether

Received March 8, 2011; revised April 5, 2011; accepted April 12, 2011.

Author contributions: S.C. and M.A.X.-F. designed research; S.C. performed research; S.C. and M.A.X.-F. analyzed data; S.C. and M.A.X.-F. wrote the paper.

This study was supported by National Institutes of Health Grant R01 DC008125 to MAX-F. We thank T. Jarsky, H. Yang, J. Trimper, Y. Yang, T. Ngodup, and T. Ruan for their comments on the manuscript.

Correspondence should be addressed to Matthew A. Xu-Friedman, Department of Biological Sciences, University at Buffalo, State University of New York, 109 Cooke Hall, Buffalo, NY 14260. E-mail: mx@buffalo.edu.

S. Chanda's present address: Stanford Institute for Neuro-innovation \& Translational Neurosciences, Stanford University, 265 Campus Drive, Stanford, CA 94305.

DOI:10.1523/JNEUROSCI.1193-11.2011

Copyright $\odot 2011$ the authors $\quad 0270-6474 / 11 / 317450-06 \$ 15.00 / 0$ there are modulatory mechanisms that maintain or enhance the response properties of BCs.

To examine these issues, we made patch-clamp recordings from $\mathrm{BCs}$ and activated mGluRs using the specific agonist DHPG. Application of DHPG depolarized BCs, but had no measurable effect on neurotransmitter release from endbulbs. The depolarization enhanced the response of BCs in response to AN activity, offsetting the effects of depression. Furthermore, mGluR activation largely restored spiking after $\mathrm{GABA}_{\mathrm{B}} \mathrm{R}$ activation, suggesting that these two modulatory pathways could interact to tune the response properties of BCs.

\section{Materials and Methods}

Experimental procedures were approved by Institutional Animal Care and Use Committee. The methods were described previously (Chanda and Xu-Friedman, 2010b). Briefly, sagittal slices (150 $\mu \mathrm{m})$ of the AVCN were cut from $\mathrm{P} 16-\mathrm{P} 42 \mathrm{CBA} / \mathrm{CaJ}$ mice of either sex. Recordings were made at $\sim 34^{\circ} \mathrm{C}$ in external solution containing the following (in $\mathrm{mm}$ ): $125 \mathrm{NaCl}, 26 \mathrm{NaHCO}_{3}, 20$ glucose, $2.5 \mathrm{KCl}, 1.25 \mathrm{NaH}_{2} \mathrm{PO}_{4}, 1 \mathrm{MgCl}_{2}, 1.5$ $\mathrm{CaCl}_{2}, 4 \mathrm{Na}$ L-lactate, $2 \mathrm{Na}$-pyruvate, $0.4 \mathrm{Na}$ L-ascorbate, and 0.01 strychnine, bubbled with $95 \% \mathrm{O}_{2}$ and $5 \% \mathrm{CO}_{2}$.

Patch pipettes were 1-2 $\mathrm{M} \Omega$, filled with (in $\mathrm{mm}$ ) $130 \mathrm{KMeSO}_{3}$ (current clamp) or $\mathrm{CsMeSO}_{3}$ (voltage clamp), $10 \mathrm{NaCl}, 10 \mathrm{HEPES}, 2 \mathrm{MgCl}_{2}, 0.5$ EGTA, $0.16 \mathrm{CaCl}_{2}, 4 \mathrm{Na}_{2} \mathrm{ATP}, 0.4 \mathrm{NaGTP}, 14$ Tris-creatine phosphate, and 1 QX-314 (voltage clamp), pH 7.3, 310 mOsm. Single AN fibers were stimulated using 6-20 $\mu \mathrm{A}$ pulses passed through a small glass micropipette placed in the neuropil. For voltage clamp, the holding potential was $-70 \mathrm{mV}$ with access resistance 3-7 $\mathrm{M} \Omega$, compensated to $70 \%$; for current clamp, we set the initial resting membrane potential $\left(V_{\text {rest }}\right)$ to -61 $\mathrm{mV}$ using a small, constant holding current, which was not adjusted thereafter except where specified. BCs were identified in current clamp by undershooting spikes (Oertel, 1983). We confirmed the morphology by including $10 \mu \mathrm{M}$ Alexa 594 (Invitrogen) in the patch pipette for some experiments (Fig. 1A). In voltage clamp, BCs were identified by pairedpulse depression and fast EPSC kinetics (Chanda and Xu-Friedman, 2010b). Methods for perforated-patch recordings are described by Chanda and Xu-Friedman (2010a). 
A

B
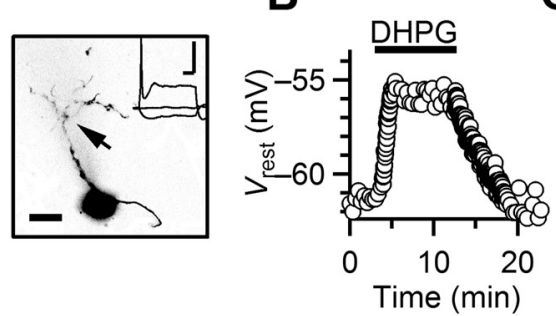

C

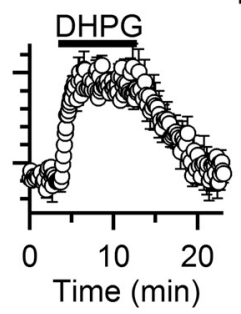

D

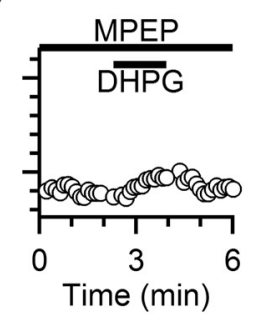

E

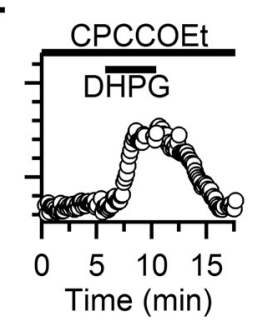

F

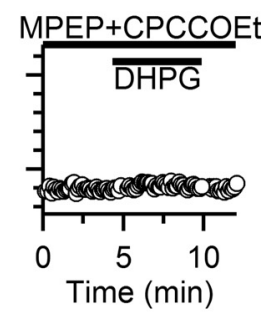

G

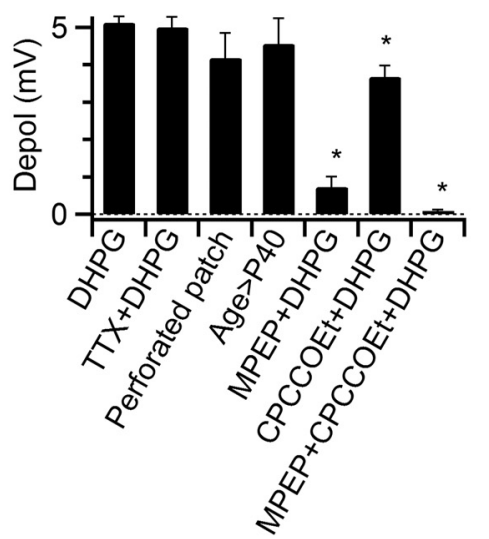

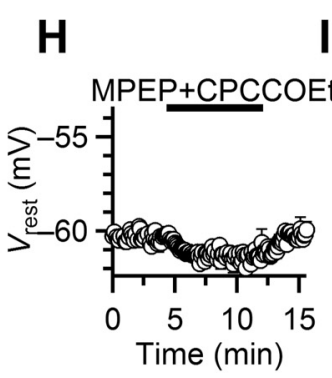
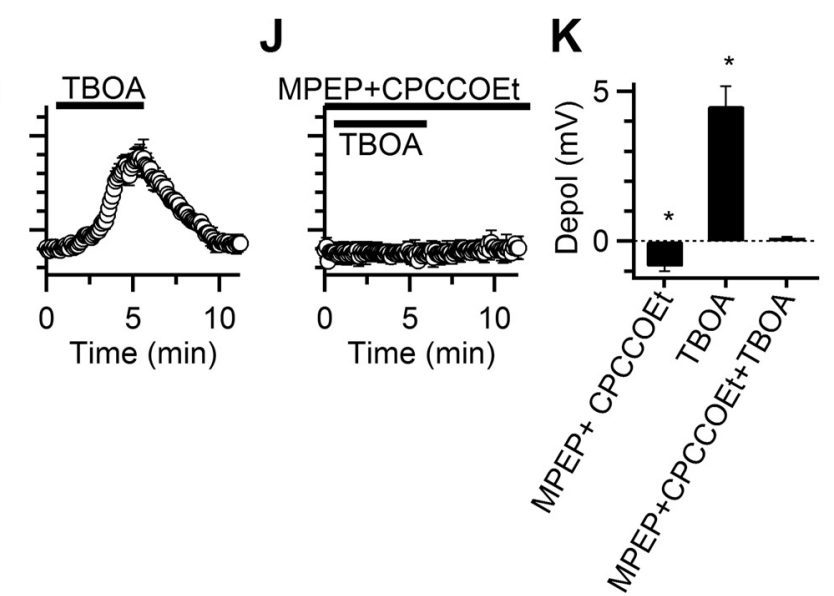

Figure 1. Activation of group I $m G$ luRs depolarizes $B C$. $A$, Confocal image of a representative $B C$ loaded with Alexa-594. Arrow indicates $B C$ dendrite. Inset, Response to current pulses of -150 , 0 , or $600 \mathrm{pA}$, used to identify the cell type. Scale bar, $10 \mu \mathrm{m}$. Calibration: $10 \mathrm{~ms}, 20 \mathrm{mV}$. B, Response of a representative BC to DHPG application. C, Average $V_{\text {rest }}$ for experiments similar to $\boldsymbol{B}$. Data points are averages of 3-7 experiments. $\boldsymbol{D}-\boldsymbol{F}$, Representative experiments showing the effects of DHPG on $V_{\text {rest }}$ in the presence of MPEP (D), CPCCOEt (E), and MPEP + CPCCOEt $(\boldsymbol{F})$. G, Relative depolarization for experiments similar to $\boldsymbol{B}-\boldsymbol{F}$. Asterisks indicate depolarizations significantly lower than in DHPG alone. Bars are averages of 3-39 experiments. $\boldsymbol{H}-\boldsymbol{J}$, Average effects on $V_{\text {rest }}$ of $\mathrm{MPEP}+\mathrm{CPCCOEt}(\boldsymbol{H}, 7$ cells), TBOA $(\boldsymbol{I}, 5$ cells), and TBOA + MPEP + CPCCOEt ( $\boldsymbol{J}, 3$ cells). $\boldsymbol{K}$, Relative depolarization for experiments similar to $\boldsymbol{H}-\boldsymbol{J}$. Asterisks indicate significant hyperpolarization or depolarization. Bars are averages of $3-9$ experiments.

A

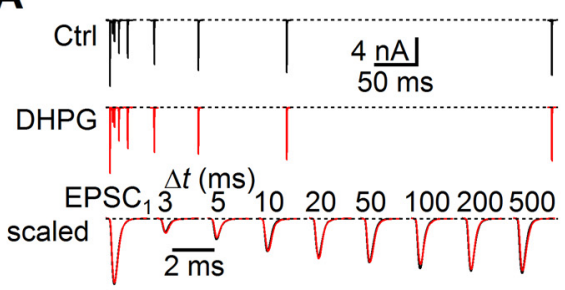

$\mathrm{Di}$

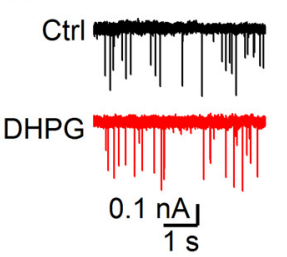

ii

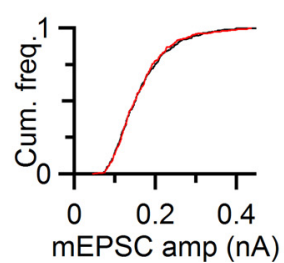

B

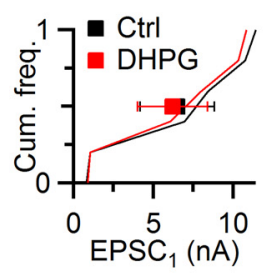

E

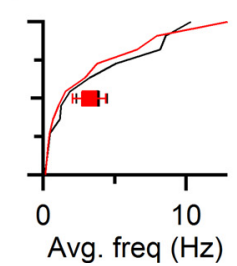

Figure 2. No presynaptic effect of DHPG at the endbulb of Held. $\boldsymbol{A}$, Representative EPSC traces recorded from a BC in control conditions (top) and in DHPG (middle) while stimulating a single AN input with pairs of pulses at different intervals. EPSCs overlaid from two conditions for comparison (bottom). $\boldsymbol{B}$, EPSC $\boldsymbol{C}_{1}$ amplitudes from six experiments similar to $\boldsymbol{A}$ plotted as a cumulative histogram. Squares represent averages in control conditions (black) and DHPG (red). C, Average paired-pulse ratio (PPR = $\left.\mathrm{EPSC}_{2} / \mathrm{EPSC}_{1}\right)$ for six cells, plotted against different interpulse intervals $(\Delta t)$. Inset expands short intervals. $D$, Effects of DHPG on $\mathrm{mEPSC}$ for a representative cell. $\boldsymbol{i}$, Example traces in control conditions and DHPG. $\boldsymbol{i i}$, Cumulative histogram of mEPSC amplitude. $\boldsymbol{E}, \boldsymbol{F}$, Cumulative histograms of mEPSC frequencies $(\boldsymbol{E})$ and amplitudes $(\boldsymbol{F})$ from 12 experiments similar to $\boldsymbol{D}$. Squares indicate overall averages.

The pharmacological agents were DHPG (group I mGluR agonist, $50 \mu \mathrm{M}$ ) (Ito et al., 1992), MPEP (mGluR5-specific antagonist, $100 \mu \mathrm{M})$ (Gasparini et al., 1999), CPCCOEt (mGluR1-specific antagonist, $100 \mu \mathrm{M}$ ) (Litschig et al., 1999), NBQX (AMPA-type glutamate receptor antagonist, $10 \mu \mathrm{M}$ ) (Shear-
C

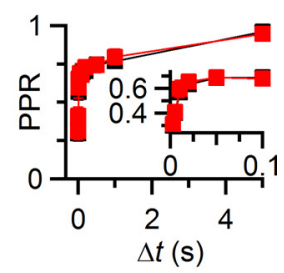

$\mathbf{F}$

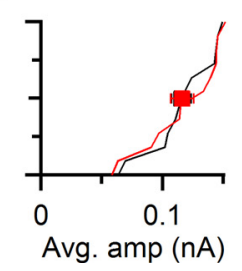

down et al., 1990), CPP (NMDA-type glutamate receptor antagonist, $5 \mu \mathrm{M}$ ) (Harris et al., 1986), TBOA (glutamate transporter antagonist, 250 $\mu \mathrm{M})$ (Shimamoto et al., 1998), GABA (50 $\mu \mathrm{M})$, TTX (voltage-gated sodium channel antagonist, $0.5 \mu \mathrm{M})$, CGP55845 (GABA $\mathrm{B}$-specific antagonist, $2 \mu \mathrm{M})$ (Brugger et al., 1993), and baclofen $\left(\mathrm{GABA}_{\mathrm{B}} \mathrm{R}\right.$-specific agonist, $2 \mu \mathrm{M}$ ) (Hill and Bowery, 1981). DHPG, MPEP, CPCCOEt, CPP, and TTX were obtained from Ascent Scientific; TBOA, CGP55845, and NBQX from Tocris Bioscience; and other chemicals from Sigma.

Data are presented as mean \pm SE. Significance was determined using the paired, one-tailed, Student's $t$ test, except where otherwise specified.

\section{Results}

\section{Activation of BC mGluRs}

We made current-clamp recordings from BCs and bath applied the group I mGluR agonist DHPG (Fig. $1 B, C$ ). DHPG depolarized BCs from $-61.1 \pm 0.1 \mathrm{mV}$ to $-56.0 \pm 0.2 \mathrm{mV}$ (39 cells, $p<0.001$ ) (Fig. $1 C, G)$. This depolarization was unaffected by TTX, suggesting a direct effect on BCs (6 cells) (Fig. $1 G)$. Similar depolarization occurred in perforated-patch experiments (7 cells) (Fig. 1G), indicating that our whole-cell recordings did not disrupt the intracellular signaling environment. Similar effects were also found in P42 animals, suggesting that mGluRs play a role in mature auditory function (3 cells) (Fig. 1G). 
A
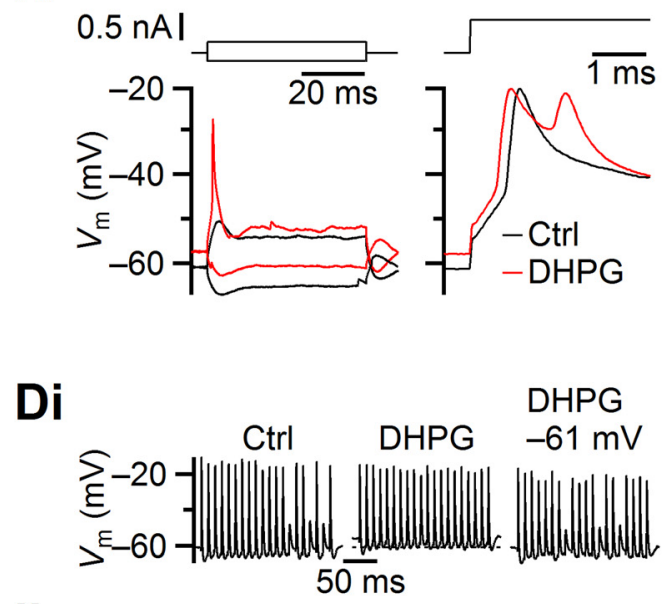

ii

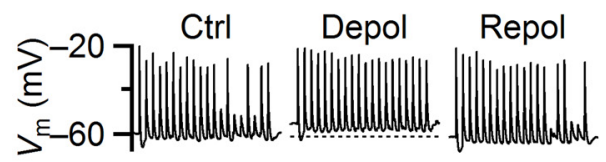

iii

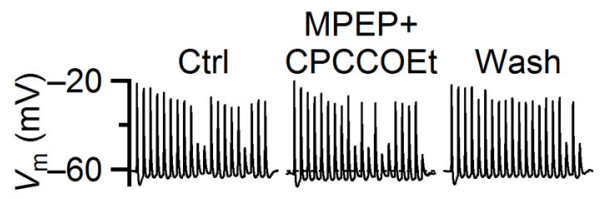

B

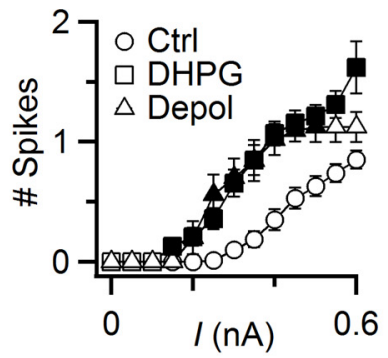

E
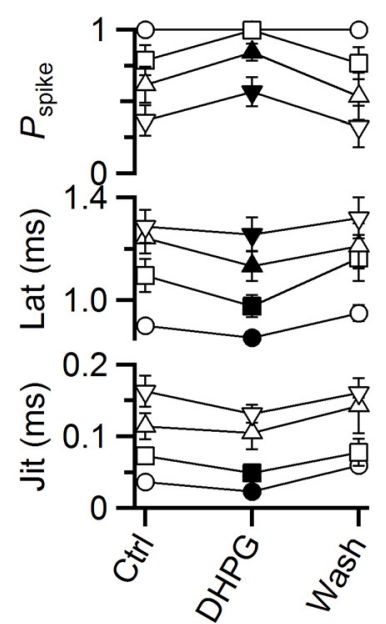

C

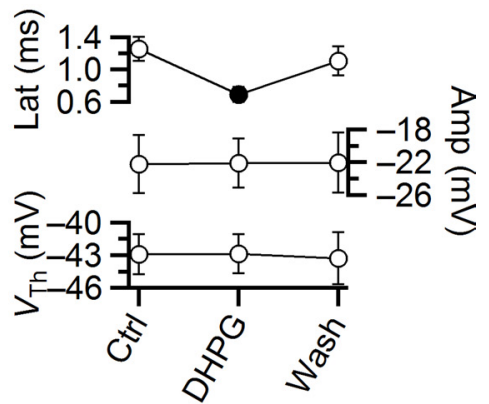

F
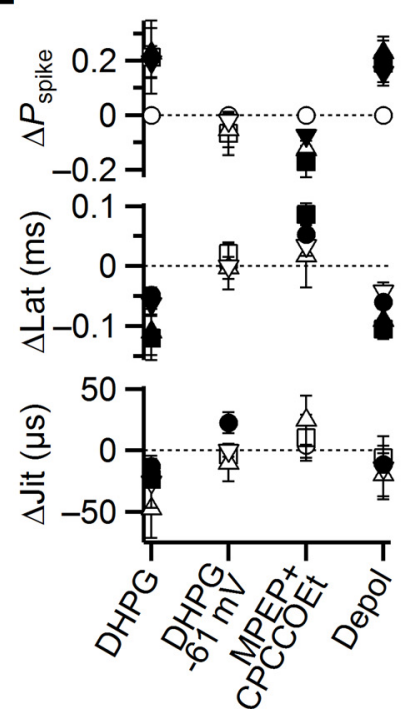

Figure 3. Effects of group I mGluR activation on spike generation in BCs. Filled symbols indicate values significantly different from control conditions $(p<0.05) . A$, Representative current-clamp traces (lower traces) in response to current pulses (upper traces) in control conditions (black) and in DHPG (red). Left, Responses to -0.15 and $0.2 \mathrm{nA}$ pulses. Right, Responses to $0.6 \mathrm{nA}$ pulses. $\boldsymbol{B}$, Average number of spikes generated for current pulses of different amplitudes from experiments similar to $A$. Squares indicate effects of DHPG ( 33 cells), and triangles indicate effects of depolarization to $-56 \mathrm{mV}$ (9 cells). C, Average measurements from 33 experiments similar to $A$, showing effects of DHPG on spike latency (top panel), peak voltage (middle), and threshold voltage (bottom). D, Modulation of BC spiking during stimulation of single AN inputs at $100 \mathrm{~Hz}$. Three representative cells show effects of DHPG and DHPG while maintaining $V_{\text {rest }}$ close to $-61 \mathrm{mV}$ with a constant holding current (i), depolarization to $-56 \mathrm{mV}$ with constant holding current (ii), and application of MPEP + CPCCOEt (iii). Dotted lines in center traces indicate $V_{\text {rest }}$ in control conditions. $E$, Average effects of DHPG on BC firing probability, latency, and jitter for seven experiments similar to Di. Spike probability and timing are quantified in response to pulse 1, and for pulses $11-20$ at 100,200 , and $333 \mathrm{~Hz}$ stimulation frequency. $\boldsymbol{F}$, Relative changes in spike probability (top), latency (middle), and jitter (bottom) for the various experimental manipulations in D. Symbols are averages of $7-9$ experiments.

We evaluated the contributions of different group I mGluR isoforms by applying specific blockers 3-5 min before DHPG. $V_{\text {rest }}$ was corrected to $-61 \mathrm{mV}$ as needed during this period, but not thereafter. Preapplication of the mGluR5-specific blocker MPEP significantly reduced the depolarization $(p<0.001$, unpaired $t$ test, 5 MPEP vs 39 control cells) (Fig. $1 D, G$ ). The mGluR1-specific blocker CPCCOEt also decreased the depolarization ( $p<0.005$, unpaired $t$ test, 5 CPCCOEt vs 39 control cells) (Fig. $1 E, G$ ). Coapplication of MPEP and CPCCOEt completely blocked the depolarization by DHPG ( $p<0.001$, unpaired $t$ test, $4 \mathrm{MPEP}+\mathrm{CPCCOEt}$ vs 39 control cells) (Fig. $1 F, G$ ). Thus, DHPG depolarizes BCs primarily through mGluR5, with a smaller contribution through mGluR1.

We also applied MPEP and CPCCOEt in the absence of DHPG, and observed a small but significant hyperpolarization (7 cells, $p<0.002$ ) (Fig. $1 H, K$ ). Furthermore, application of the glutamate reuptake inhibitor TBOA (in the presence of CPP and NBQX, which are NMDA and AMPA receptor antagonists, respectively) significantly depolarized the BC ( 9 cells, $p<0.001$ ) (Fig. $1 I, K)$. TBOA-induced depolarization was blocked in MPEP + CPCCOEt ( 3 cells, $p>0.1$ ) (Fig. $1 J, K$ ). These results indicate that mGluRs on BCs are sensitive to fluctuations in ambient glutamate concentration.

\section{Presynaptic effects}

At the calyx of Held, mGluR activation by DHPG drives release of endocannabinoids, which reduce presynaptic neurotransmitter release (Kushmerick et al., 2004). We tested this possibility at the endbulb by making voltage-clamp recordings from BCs and stimulating presynaptic AN fibers with pairs of pulses at different intervals. Application of DHPG had no significant effect on the amplitude or kinetics of the first EPSC $\left(\right.$ EPSC $\left._{1}\right)($ Fig. $2 A, B)$ or the second EPSC in a pair ( $p>0.2,6$ cells) (Fig. $2 A, C)$. These results indicate that mGluR activation does not affect the probability of release at the endbulb.

We also confirmed that other aspects of synaptic transmission were unaffected by mGluR activation by examining mEPSCs in the presence of TTX (Fig. $2 D)$. Neither the frequency $(p>0.2)$ (Fig. $2 E$ ) nor the amplitude ( $p>0.4,12$ cells) (Fig. $2 F$ ) of mEPSCs changed significantly with DHPG application. This indicates that mGluR activation had no effect on postsynaptic AMPA receptors, nor on the presynaptic release machinery.

\section{Effect of mGluR activation on postsynaptic firing}

We next examined how mGluRs influenced spike generation in BCs. In an example experiment, a $0.2 \mathrm{nA}$ depolarizing current pulse triggered a spike in the presence of DHPG but not in con- 
$\mathrm{Ai}$

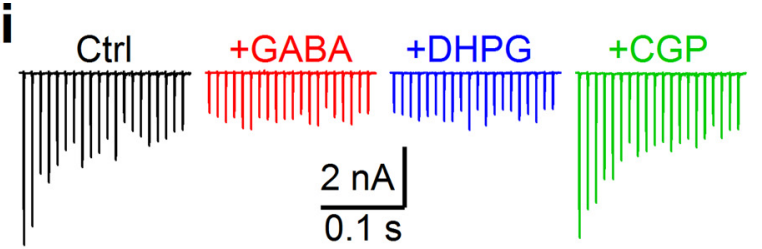

B

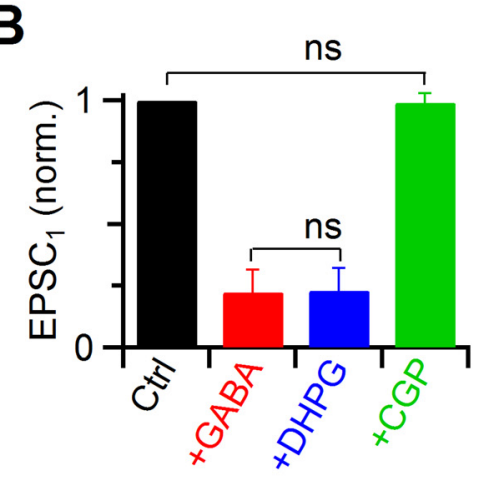

C

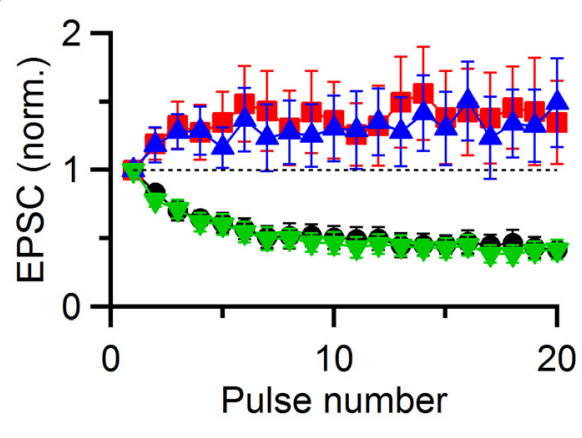

D

E
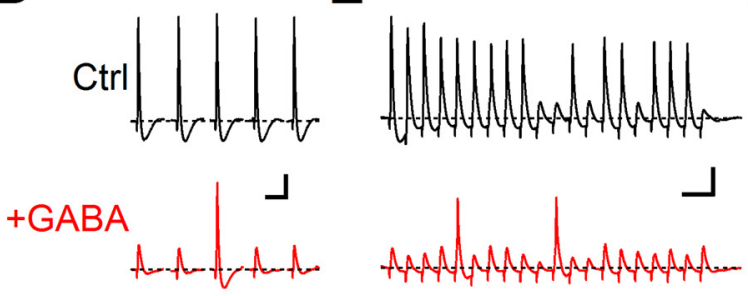

$\mathbf{F}$
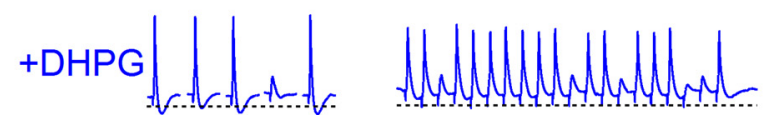
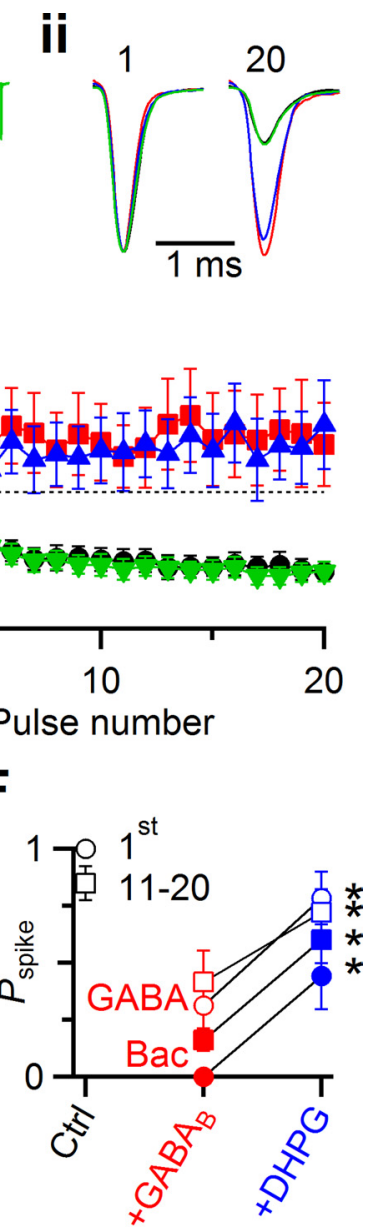

Figure 4. Interaction between $\mathrm{GABA}_{B} \mathrm{R}$ - and mGluR-mediated modulation. $\boldsymbol{A}$, Representative voltage-clamp experiment showing presynaptic effects of $50 \mu \mathrm{m}$ GABA on EPSCs during $100 \mathrm{~Hz}$ trains of AN activation. Compared to control (black), EPSCs in GABA are reduced, and show facilitation (red). Addition of DHPG has no further effect (blue), and all the effects are blocked by the

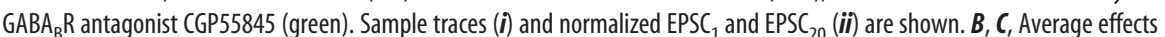
of GABA and DHPG from five experiments. The effects on EPSC $\boldsymbol{C}_{1}$ amplitude $(\boldsymbol{B})$ and normalized train EPSCS $(\boldsymbol{C})$ are shown. The amplitude of EPSC ${ }_{1}$ does not differ significantly between $G A B A$ and GABA + DHPG $(p>0.2)$. The EPSC in GABA+DHPG + CGP is not significantly different from control $(p>0.3) . \boldsymbol{D}, \boldsymbol{E}$, Two representative experiments showing the interaction between mGluR and $G_{A B A}$ R activation in current clamp. AN inputs were stimulated with single pulses $(\boldsymbol{D})$ or a train of 20 pulses at $100 \mathrm{~Hz}(\boldsymbol{E})$. The effects on $B C$ spiking were recorded in control conditions (upper traces), in the presence of GABA (middle), and in DHPG $+G A B A$ (lower). Dotted lines indicate $V_{\text {rest }}$ in control conditions. Calibration: $10 \mathrm{mV}, 20 \mathrm{~ms}$. F, Average firing probabilities for experiments similar to $\boldsymbol{D}$ and $\boldsymbol{E}$ using GABA (red and blue open symbols, 6 cells), or baclofen (closed symbols, 5 cells).

less reliable at later pulses (Fig. 3Di, left), presumably because of synaptic depression. DHPG application increased the probability of spiking for those later pulses (Fig. 3Di, middle). We considered the effects of mGluR activation on spike probability and timing for the first pulse, as well as for pulses 11-20, where the EPSC amplitudes are near steady-state levels of depression. We quantified spike latency from each stimulus to the immediately following spike, and spike jitter as $\mathrm{SD}$ in the latency. In DHPG, the spike probability increased for the steady-state part of the train, and spike latency and jitter both decreased ( 7 cells, $p<0.05$ ) (Fig. 3E). Repolarizing the $\mathrm{BC}$ to $-61 \mathrm{mV}$ using current injection, in the continued presence of DHPG, reversed the changes in firing probability, latency, and jitter (9 cells) (Fig. 3Di, right, F). Furthermore, depolarizing the $\mathrm{BC}$ to $-56 \mathrm{mV}$ in the absence of DHPG had nearly identical effects ( 8 cells, $p<0.05$ ) (Fig. $3 D i i, F)$, suggesting that the increase in firing could be accounted for by simple depolarization.

We also examined how the endogenous, tonic activation of mGluRs influenced BC firing. Application of MPEP+ CPCCOEt decreased the spike probability for 200 and $333 \mathrm{~Hz}$ trains, while the latency of the first pulse and of $100 \mathrm{~Hz}$ trains increased significantly ( 7 cells, $p<0.05$ ) (Fig. 3Diii,F). There was no significant change in jitter. Thus, the tonic mGluRdependent depolarization had a measurable impact on the firing properties of BCs.

We wanted to understand how mGluR activation could interact with the larger modulatory environment of the AVCN, particularly the inhibitory modulator GABA. Application of $50 \mu \mathrm{M}$ GABA blocked EPSC $_{1}$ by $>75 \%$ (Fig. $4 A, B$ ) and trol conditions (Fig. 3A, left). A greater current pulse (0.6 nA) led to spiking in both cases, but DHPG application led to an additional spike (Fig. $3 A$, right). On average, mGluR activation increased the number of spikes and decreased the latency of the first spike ( 33 cells, $p<0.002$ ) (Fig. $3 B, C$ ) without significantly affecting the AP peak or threshold voltage $(p>0.2)$ (Fig. $3 C$ ). These effects could have resulted simply from depolarization bringing the $\mathrm{BC}$ closer to threshold. We used a small holding current to depolarize BCs to a $V_{\text {rest }}$ of $-56 \mathrm{mV}$ in the absence of DHPG. Subsequent application of current pulses under these conditions also led to increased spiking, similar to that in DHPG (8 cells) (Fig. 3B). This indicates that the principal effects of mGluR activation on spiking are mediated through depolarization.

We next studied how DHPG affected BC spiking during AN activity (Fig. 3D). We activated AN fibers using trains of 20 stimuli at physiological firing rates $(100,200$, and $333 \mathrm{~Hz})$. In control conditions, BCs fired reliably early in $100 \mathrm{~Hz}$ trains, but became changed short-term plasticity from depressing to facilitating (Fig. $4 A, C)$, reflecting a drop in the presynaptic release probability (Chanda and Xu-Friedman, 2010a). Further application of DHPG had no additional effect (Fig. $4 A-C$ ), indicating that the two modulators have no synergistic presynaptic interaction. Application of CGP55845 restored the EPSC to control levels (Fig. $4 A-C$ ), confirming that GABA acted through presynaptic $\mathrm{GABA}_{\mathrm{B}} \mathrm{R}$.

We examined the consequences of these effects on the EPSC using current-clamp recordings. Single AN stimuli caused reliable spiking (Fig. $4 D$, top traces), but after applying GABA, many EPSPs failed to elicit spikes (middle traces in Fig. $4 D$, open red symbols in Fig. $4 F$ ). This did not result from postsynaptic effects of GABA as there were no significant changes in $V_{\text {rest }}$ (Fig. $4 D, E$, middle traces) $(-60.6 \pm 0.2 \mathrm{mV}$ in control conditions vs $-60.9 \pm 0.2 \mathrm{mV}$ in GABA, $p>0.05,6$ cells), action potential threshold $(-42.9 \pm 0.9 \mathrm{mV}$ in control conditions vs $-43.9 \pm 1.2$ 
$\mathrm{mV}$ in GABA, $p>0.05,4$ cells), or input resistance ( $40.9 \pm 2.9$ $\mathrm{M} \Omega$ in control conditions vs $42.3 \pm 6.4 \mathrm{M} \Omega$ in $\mathrm{GABA}$ at $-61 \mathrm{mV}$, $p>0.3,4$ cells). Furthermore, GABA had similar effects on BC firing even in the presence of $\mathrm{GABA}_{\mathrm{A}}$ receptor antagonist bicuculline (data not shown). Thus, the drop in spiking was likely caused by the decrease in EPSP amplitude following $G_{A B A} R$ activation.

When we next added DHPG, firing was restored to a considerable extent (Fig. $4 D, E$, bottom traces). In six experiments, GABA application reduced the firing probability throughout the train (Fig. $4 F)(p<0.003)$, and mGluR activation significantly restored it $(p<0.005)$ (Fig. $4 F$, open blue symbols). We confirmed that GABA activated $\mathrm{GABA}_{\mathrm{B}}$ Rs using CGP55845: the firing probability in DHPG alone was the same as in DHPG + GABA + CGP $\left(P_{\text {spike }}=1 \pm 0\right.$ in both conditions for pulse 1 , and $0.91 \pm 0.07$ vs $0.90 \pm 0.08$ for pulses $11-20, p>0.5$, 3 cells). Similarly, in five experiments, spiking was strongly blocked by the $\mathrm{GABA}_{\mathrm{B}} \mathrm{R}$-specific agonist baclofen $(p<0.001)$, and subsequent DHPG application caused significant recovery $(p<0.02)$ (Fig. $4 F$, closed symbols).

\section{Discussion}

We show here that group I mGluRs play an active role in modulating $\mathrm{BC}$ membrane potential. mGluR-mediated depolarization enhances firing properties of BCs in response to AN activity. Hyperpolarization by mGluR antagonists and depolarization by the glutamate reuptake inhibitor TBOA indicate that ambient glutamate is sufficient to activate mGluRs, and the membrane potential could be sensitive to fluctuations in local glutamate concentration. We also show that this excitatory modulation can interact with inhibitory modulation to enhance or suppress the efficacy of AN endbulbs at driving BCs to fire spikes. This could provide considerable flexibility in the functional state of this synapse.

The fidelity of spiking in BCs is particularly important because they relay temporal information about sounds to higher centers. Activation of mGluRs increased the probability of $\mathrm{BC}$ spiking by $20 \%$ during trains of activity, while blocking the tonic activation decreased spike probability by $10 \%$. Thus, these receptors influence spike probability over a wide range. Furthermore, mGluR activation decreased spike latency by $>100 \mu \mathrm{s}$, much greater than the behavioral sensitivity to timing in the auditory system, which is on the order of $10 \mu$ s (Klumpp and Eady, 1956). Thus, mGluRs likely have a large impact on BCs' role in the sound localization pathway.

Group I mGluRs do not appear to influence neurotransmitter release from the endbulb. This differs from the related calyx of Held, where mGluR activation by itself is sufficient to cause endocannabinoid release (Kushmerick et al., 2004). Activation of mGluRs alone can also drive endocannabinoid release in hippocampus and cerebellum (Maejima et al., 2001; Varma et al., 2001; Brown et al., 2003). Endbulbs do appear to express cannabinoid receptors (our unpublished observations), but DHPG evidently is insufficient to activate them. Thus endocannabinoid release in the AVCN probably requires other factors.

Our experiments provide insights into how mGluRs may be normally activated. In our slice experiments, mGluRs were tonically active, and TBOA increased that activation. AN fibers form the only known glutamatergic terminals onto BCs, but they are silent in slices, except for infrequent mEPSC release $(<5$ vesicles/s). It is unclear whether this would be sufficient to activate mGluRs. Alternatively, glutamatergic sources other than endbulbs may have been overlooked if their synapses lack conventional, AMPA receptor-mediated EPSCs. Another possibility is that mGluRs are extrasynaptic and sense the ambient level of glutamate in the environment. This glutamate signal could be contributed to by multiple cell types in the AVCN, including stellate cells and BCs themselves, as a global indicator of activity, similar to what has been proposed for nitric oxide in the superior olive (Steinert et al., 2008). Additional experiments will be necessary to evaluate these different possibilities.

Our results establish a clear distinction between the mGluR and $\mathrm{GABA}_{\mathrm{B}} \mathrm{R}$ systems, that they act at separate loci, one presynaptic and one postsynaptic. We study for the first time how these two systems could interact. Our results indicate that this may give important flexibility to the AN to BC synapse, which could affect its function during sound processing. One possibility is that these two pathways are triggered independently, and GABA and glutamate sources compete to push the BC relay toward more or less reliable (Fig. 4). Alternatively, the two pathways could be coordinated to extend the dynamic range of the synapse. For example, when AN fibers fire at high rates, mGluR activation could allow them to drive BCs effectively despite short-term depression. At low AN firing rates, the endbulb shows little depression and is highly saturating; $\mathrm{GABA}_{\mathrm{B}} \mathrm{R}$ activation would keep it below saturated levels so firing is not at $100 \%$ probability. Another interesting possibility is that $\mathrm{GABA}_{\mathrm{B}} \mathrm{R}$ activation could be input specific, while the effects of mGluR activation could affect all synaptic inputs at once. It would be interesting to evaluate these different scenarios by applying specific blockers of these receptors during normal sound processing in vivo (Brückner and Hyson, 1998; Fukui et al., 2010). It will also be important to evaluate how the depolarization caused by mGluR activation interacts with the other inhibitory influences, e.g., $\mathrm{GABA}_{\mathrm{A}}$ and glycine receptor activation (Wu and Oertel, 1986; Caspary et al., 1994; Kopp-Scheinpflug et al., 2002; Gai and Carney, 2008).

\section{References}

Anwyl R (1999) Metabotropic glutamate receptors: electrophysiological properties and role in plasticity. Brain Res Rev 29:83-120.

Brawer JR, Morest DK (1975) Relations between auditory nerve endings and cell types in the cat's anteroventral cochlear nucleus seen with the Golgi method and Nomarski optics. J Comp Neurol 160:491-506.

Brown SP, Brenowitz SD, Regehr WG (2003) Brief presynaptic bursts evoke synapse-specific retrograde inhibition mediated by endogenous cannabinoids. Nat Neurosci 6:1048-1057.

Brückner S, Hyson RL (1998) Effect of GABA on the processing of interaural time differences in nucleus laminaris neurons in the chick. Eur J Neurosci 10:3438-3450.

Brugger F, Wicki U, Olpe HR, Froestl W, Mickel S (1993) The action of new potent $G A B A B$ receptor antagonists in the hemisected spinal cord preparation of the rat. Eur J Pharmacol 235:153-155.

Caspary DM, Backoff PM, Finlayson PG, Palombi PS (1994) Inhibitory inputs modulate discharge rate within frequency receptive fields of anteroventral cochlear nucleus neurons. J Neurophysiol 72:2124-2133.

Chanda S, Xu-Friedman MA (2010a) Neuromodulation by GABA converts a relay into a coincidence detector. J Neurophysiol 104:2063-2074.

Chanda S, Xu-Friedman MA (2010b) A low-affinity antagonist reveals saturation and desensitization in mature synapses in the auditory brain stem. J Neurophysiol 103:1915-1926.

Ene FA, Kalmbach A, Kandler K (2007) Metabotropic glutamate receptors in the lateral superior olive activate TRP-like channels: age- and experience-dependent regulation. J Neurophysiol 97:3365-3375.

Ferraguti F, Crepaldi L, Nicoletti F (2008) Metabotropic glutamate 1 receptor: current concepts and perspectives. Pharmacol Rev 60:536-581.

Fukui I, Burger RM, Ohmori H, Rubel EW (2010) GABAergic inhibition sharpens the frequency tuning and enhances phase locking in chicken nucleus magnocellularis neurons. J Neurosci 30:12075-12083.

Gai Y, Carney LH (2008) Influence of inhibitory inputs on rate and timing 
of responses in the anteroventral cochlear nucleus. J Neurophysiol 99:1077-1095.

Gasparini F, Lingenhöhl K, Stoehr N, Flor PJ, Heinrich M, Vranesic I, Biollaz M, Allgeier H, Heckendorn R, Urwyler S, Varney MA, Johnson EC, Hess SD, Rao SP, Sacaan AI, Santori EM, Veliçelebi G, Kuhn R (1999) 2-Methyl-6-(phenylethynyl)-pyridine (MPEP), a potent, selective and systemically active mGlu5 receptor antagonist. Neuropharmacology 38:1493-1503.

Grothe B, Pecka M, McAlpine D (2010) Mechanisms of sound localization in mammals. Physiol Rev 90:983-1012.

Harris EW, Ganong AH, Monaghan DT, Watkins JC, Cotman CW (1986) Action of 3-((+/-)-2-carboxypiperazin-4-yl)-propyl-1-phosphonic acid (CPP): a new and highly potent antagonist of N-methyl-D-aspartate receptors in the hippocampus. Brain Res 382:174-177.

Hill DR, Bowery NG (1981) 3H-baclofen and 3H-GABA bind to bicuculline-insensitive GABA B sites in rat brain. Nature 290:149-152.

Ito I, Kohda A, Tanabe S, Hirose E, Hayashi M, Mitsunaga S, Sugiyama H (1992) 3,5-Dihydroxyphenyl-glycine: a potent agonist of metabotropic glutamate receptors. Neuroreport 3:1013-1016.

Klumpp RG, Eady HR (1956) Some measurements of interaural time difference thresholds. J Acoust Soc Am 28:859-860.

Kopp-Scheinpflug C, Dehmel S, Dörrscheidt GJ, Rübsamen R (2002) Interaction of excitation and inhibition in anteroventral cochlear nucleus neurons that receive large endbulb synaptic endings. J Neurosci 22:11004-11018.

Kushmerick C, Price GD, Taschenberger H, Puente N, Renden R, Wadiche JI, Duvoisin RM, Grandes P, von Gersdorff H (2004) Retroinhibition of presynaptic $\mathrm{Ca}^{2+}$ currents by endocannabinoids released via postsynaptic mGluR activation at a calyx synapse. J Neurosci 24:5955-5965.

Limb CJ, Ryugo DK (2000) Development of primary axosomatic endings in the anteroventral cochlear nucleus of mice. J Assoc Res Otolaryngol 1:103-119.

Litschig S, Gasparini F, Rueegg D, Stoehr N, Flor PJ, Vranesic I, Prézeau L, Pin JP, Thomsen C, Kuhn R (1999) CPCCOEt, a noncompetitive metabotropic glutamate receptor 1 antagonist, inhibits receptor signaling without affecting glutamate binding. Mol Pharmacol 55:453-461.
Lorente de Nó R (1981) The primary acoustic nuclei. New York: Raven.

Maejima T, Hashimoto K, Yoshida T, Aiba A, Kano M (2001) Presynaptic inhibition caused by retrograde signal from metabotropic glutamate to cannabinoid receptors. Neuron 31:463-475.

Martinez-Galan JR, Perez-Martinez FC, Juiz JM (2010) Differences in glutamate-mediated calcium responses in the ventral cochlear nucleus and inferior colliculus of the developing rat. Hear Res 267:46-53.

Oertel D (1983) Synaptic responses and electrical properties of cells in brain slices of the mouse anteroventral cochlear nucleus. J Neurosci 3:2043-2053.

Oleskevich S, Walmsley B (2002) Synaptic transmission in the auditory brainstem of normal and congenitally deaf mice. J Physiol 540:447-455.

Sheardown MJ, Nielsen EO, Hansen AJ, Jacobsen P, Honoré T (1990) 2,3Dihydroxy-6-nitro-7-sulfamoyl-benzo(F)quinoxaline: a neuroprotectant for cerebral ischemia. Science 247:571-574.

Shimamoto K, Lebrun B, Yasuda-Kamatani Y, Sakaitani M, Shigeri Y, Yumoto N, Nakajima T (1998) DL-threo-beta-benzyloxyaspartate, a potent blocker of excitatory amino acid transporters. Mol Pharmacol 53:195-201.

Steinert JR, Kopp-Scheinpflug C, Baker C, Challiss RA, Mistry R, Haustein MD, Griffin SJ, Tong H, Graham BP, Forsythe ID (2008) Nitric oxide is a volume transmitter regulating postsynaptic excitability at a glutamatergic synapse. Neuron 60:642-656.

Varma N, Carlson GC, Ledent C, Alger BE (2001) Metabotropic glutamate receptors drive the endocannabinoid system in hippocampus. J Neurosci 21:RC188.

Wang Y, Manis PB (2008) Short-term synaptic depression and recovery at the mature mammalian endbulb of Held synapse in mice. J Neurophysiol 100:1255-1264.

Wu SH, Oertel D (1986) Inhibitory circuitry in the ventral cochlear nucleus is probably mediated by glycine. J Neurosci 6:2691-2706.

Yang H, Xu-Friedman MA (2008) Relative roles of different mechanisms of depression at the mouse endbulb of Held. J Neurophysiol 99:2510-2521.

Zirpel L, Rubel EW (1996) Eighth nerve activity regulates intracellular calcium concentration of avian cochlear nucleus neurons via a metabotropic glutamate receptor. J Neurophysiol 76:4127-4139. 